Matjaž Babič

Filozofska fakulteta

Ljubljana

\title{
RAZISKOVANJE BESEDNEGA REDA V KLASIČNIH JEZIKIH
}

Besedni red $\mathrm{v}$ klasičnih jezikih je za današnje raziskovalce eden najtrših jezikovnih orehov. Prav tu se najizraziteje pokaže, kako težko je raziskovati jezik, kadar imamo na voljo podatke samo v pismeni obliki. Manjka izgovorna podoba in vse, kar bi se lahko naučili iz nje. Ni težko najti zaznamovanih vzorcev, teže je najti izhodiščne primere, torej primere za naravni besedni red $\mathrm{v}$ sobesedilno manj vezanih stavkih in besednih skupinah. $V$ takšnih okoliščinah nam tudi statistični podatki ne dajo trdne opore, saj ne vemo, ali smo prišli do njih po pravi poti.

$\mathrm{V}$ pričujočem sestavku bomo poskusili na podlagi veljavnih ugotovitev o besednem redu $\mathrm{v}$ latinščini nakazati nekaj smeri, v katere bi se lahko razvijale morebitne poznejše raziskave. Do dokončnih rešitev zaradi zgoraj naštetih (in še drugih) težav ni moč priti, a gotovo bi se dalo iti še korak ali dva naprej.

\section{OBRAVNAVA BESEDNEGA REDA V LATINSKI SLOVNICI PROF. KOPRIVE}

V Latinski slovnici prof. Koprive ${ }^{1}$ izvemo o besednem redu v latinščini marsikaj. Poglavje o besednem redu se uvaja na str. $329 \mathrm{z}$ naslednjimi besedami: "Moderni jeziki, ki so več ali manj izgubili obrazila pri sklanjatvi in spregatvi, imajo za besedni red določena, stalna pravila. Neprimerno večjo svobodo v razporejanju besed pa ima latinščina zaradi obrazil, ki ji omogočajo, da jasno in določno izraža besedna razmerja."

Nato v opombi: "Tudi v slovenščini je besedni red precej svoboden zaradi bogastva oblik in izrazil."

Nadaljuje: "To svobodo so uporabljali pisatelji in govorniki iz retoričnih razlogov in zaradi blagoglasja."

Besedni red se v Latinski slovnici deli na:

- t.i. gramatični besedni red,

- t.i. retorični (pravi mu tudi umetni ali invertirani),

- t.i. običajni ali uzualni besedni red.

GRAMATIČNı BESEDNI RED se $\mathrm{v}$ naši latinski slovnici utemeljuje zlasti s pojmom 'važnost': govor je o najvažnejših mestih v stavku (začetek in konec stavka), a na žalost ni čisto jasno, kaj naj razumemo pod izrazom 'važen'. Glasovno poudarjen? Važen po pomenu? Nepogrešljiv v slovnični zgradbi? Vse možnosti so odprte.

\footnotetext{
' Kopriva, S., Latinska slovnica, Ljubljana 1976
} 
Tudi pri t.i. RETORIČNEM BESEDNEM REDU naj bi si besede delile mesta $\mathrm{v}$ stavku po zgoraj imenovani 'važnosti': začetek dobi najvažnejša, konec druga najvažnejša. Za primer imamo stavek

(1) - Malum mihi videtur esse mors.

(str. 330): samostalnik mors naj bi kot druga najvažnejša beseda stal na zadnjem mestu v stavku. Toda pri takšnem izvajanju se prav lahko znajdemo $v$ začaranem krogu: pisec je postavil besedi malum in mors na začetek in konec, ker sta se mu zdeli važni; da sta se mu zdeli važni, sklepamo po dejstvu, da ju je postavil na začetek in konec stavka. Medtem ko nam v živem jeziku iz zagate pomaga jezikovni občutek, še zlasti za glasovno podobo stavka, se moramo $v$ mrtvem jeziku od primera do primera reševati, kakor vemo in znamo.

OBIČAJNI ALI UZUALNI BESEDNI RED naj bi bil tisti, ki ga je, kot beremo na str. 330, "ustvarilo ljudstvo v vsakdanjem govoru". Ob takšni oznaki se vprašamo, ali ni morda ljudstvo $v$ vsakdanjem govoru ustvarilo tudi slovničnega besednega reda. $V$ duhu antičnih slovničarjev se vprašamo, ali je nastal slovnični besedni red $\phi u ́ \sigma \varepsilon ı$ (po naravi) ali $\theta \varepsilon \sigma \varepsilon l$ (po dogovoru). Ko bi bil slovnični besedni red posledica notranje jezikovne nuje, bi moral biti v vseh jezikih enak, a vemo, da ni tako. V slovenščini imamo npr. povedek navadno sredi stavka: je potemtakem najvažnejše mesto sredina stavka?

$\mathrm{V}$ poglavju o običajnem besednem redu Latinske slovnice so zbrana pravila za priporočljivo stavo posameznih besed. Poglavje je sestavljeno po opisnem načelu, zato $v$ njem stavčni členi niso ločeni od posameznih besednih vrst ali celo slovničnih oblik kot vokativ (str. 333). K razlagi je treba pripomniti, da stave veznikov na prvo ali drugo mesto ni ustvarilo ljudstvo (če mislimo na rimsko ljudstvo), temveč je podedovana iz indoevropščine (t.i. Wackernaglov zakon) ${ }^{2}$.

\section{UPORABNOST PRAVIL O BESEDNEM REDU KLASIČNIH JEZIKOV ZA SLOVENŠČINO}

Predpostavimo, da je bilo $\mathrm{z}$ besednim redom $\mathrm{v}$ latinščini podobno kot $\mathrm{v}$ slovenščini in poskusimo pravila o latinskem besednem redu predelati za naš jezik. Glasila bi se nekako takole:

- osnovni besedni red je osebek - povedek - predmet;

- če hočemo katero izmed besed $v$ stavku posebej poudariti, jo postavimo na začetek ali konec;

- za stavo nekaterih besed veljajo posebna pravila.

Kmalu vidimo, da so našteta tri pravila za določanje besednega reda $v$ slovenščini premalo. Vzemimo za zgled slovenski stavek

(2) - Na Bledu bo od 23. do 31 marca potekal 17. šahovski festival.

Po stavčnih členih je besedni red v navedenem primeru :

prisl. dol. kraja - prisl. dol. časa - povedek - osebek

\footnotetext{
2 Prim. Über ein Gesetz der indogermanischen Wortstellung; Wackernagel, J. Kleine Schriften I, Göttingen 1953, 1-104
} 
Prekršili smo vsa pravila slovničnega besednega reda, ne da bi zvenel stavek vzvišeno ali slogovno zaznamovano. Kaj je pri prislovnih določilih na Bledu in od 23. do 31. marca tako 'važnega', da morata stati na začetku? Ali je takšna stava izraz slovničnega retoričnega ali uzualnega besednega reda? Kaj pomeni 'važen'? Ali je beseda 'važna' zaradi pomena nasploh ali samo zato, ker je pomembna na danem mestu v besedilu? Ali je beseda $v$ besedilu, ko jo uporabimo desetič, enako 'važna' kot takrat, ko jo uporabimo prvič? A lahko se tolažimo $z$ ugotovitvijo, da obdelujemo slovenski stavek in ne latinskega.

\section{UPORABNOST PRAVIL V LATINŠČINI}

Toda poskusimo z latinskim besedilom:

(3) - Omnium malorum stultitia est mater atque materies. Ea parit immensas cupiditates. Immensae porro cupiditates infinitae, immoderatae sunt. Hae pariunt avaritiam. Avaritia porro hominem ad quodvis maleficium impellit. Ergo avaritia inducti adversarii nostri hoc in se facinus admiserunt.

Oglejmo si zaenkrat samo tisto, kar najbolj bode v oči:

- Zakaj je póvejek od šestih primerov samo trikrat na koncu stavka?

- Zakaj je v prvem stavku pomožni glagol pred povedkovim določilom in v tretjem za njim?

- Zakaj osebek $v$ prvem in zadnjem stavku ni ne na prvem ne na zadnjem mestu? Zakaj je sredi stavka?

Še en primer. Zaporedje stavčnih členov, kakršno mora biti v lepi latinščini, lahko ponazorimo s pregovorom

(4) - Homo homini lupus est.

$\mathrm{Na}$ začetku je osebek, na koncu povedek (povedkovo določilo in pomožni glagol), med njima bližje povedkovo dopolnilo v dajalniku. Lepše bi skoraj ne moglo biti. Pregovor je izpričan že pri Plavtu v komediji Asinaria (verz 495):

(5) - Lupus est homo homini, non homo, quando, qualis sit, non novit.

Kot vidimo, so besede močno premešane: najprej povedek, nato osebek, na koncu povedkovo dopolnilo v dajalniku. Lahko bi se izgovorili na metrum, a bolje je, da si pustimo metrum za izhod v skrajni sili. Zlasti ob metrični svobodi, kot si jo je bil vzel Plavt, si je težko misliti, da bi beseda $v$ verzu ne mogla stati drugod ravno zaradi metra.

\section{LATINŠČINA IN STAVA POVEDKA V ROMANSKIH JEZIKIH}

Da s stavo povedka $v$ latinščini ni bilo tako preprosto, kot se zdi na prvi pogled, nam priča tudi dejstvo, da v romanskih jezikih povedkov glagol praviloma ne stoji na koncu stavka. Dejstvo bi se dalo razložiti razvojno, da povedek $v$ vulgarni latinščini proti koncu antike pač ni več stal na koncu stavka. $V$ indoevropščini je bi] povedkov glagol na koncu vsaj $v$ glavnih stavkih, medtem ko se za stavo $v$ odvisnikih mnenja razhajajo ${ }^{3}$. Navedimo ugotovitev iz Uvoda $v$ romansko jezikoslovje prof.

\footnotetext{
${ }^{3}$ Prim. H.H. Hock, Principles of historical linguistics, Berlin - New York 1991, str. 330.
} 
Mitje Skubica ${ }^{4}$ (str. 226): "Latinisti so natanko preiskali nekaj važnejših literarnih besedil in ugotovili, da število stavkov z glagolom na koncu pada, bolj ko gremo proti koncu antike." Stanje je prikazano $\mathrm{z}$ naslednjo razpredelnico:

Glagol na koncu (v odstotkih):

pisec:

neodvisni stavek:

odvisnik:

Cezar

Livij

Petronij

Apulej (Amor in Psiha)

Peregrinatio Egeriae

Avguštin (De civitate dei)

Oglejmo si dve podobni besedili in skušajmo ugotoviti, ali je res tako. Najprej nagrobni napis iz leta 526 po $\mathrm{Kr}$. (ILCV ${ }^{2} 1469$ ):

(6) - Hic requiescit in pace ancilla Christi Maxima, quae vixit annos plusminus XXV; deposita ante diem VIIII Kalendas Iulias Flavio Probo Iuniore viro clarissimo consule; que fecit cum maritum suum annos VII, menses VI, amicabilis, fidelis in omnibus, bona, prudens.

$\mathrm{Da}$ je jezik dovolj ljudski, se vidi iz oblike števnika ' 9 ' in pisave que, a še bolj iz zveze cum maritum suum, saj se predlog cum tukaj veže $z$ akuzativom. Če iščemo povedkov glagol, ga najdemo sredi stavka, kot je v vulgarni latinščini 6 . stoletja tudi pričakovati.

Navedimo starejši primer, enega izmed znamenitih Elogia Scipionum. dejstvo, da je napisan v verzih, bomo, podobno kot zgoraj pri Plavtu, pustili ob strani. $\mathrm{CIL}^{2}$ 8/9:

(7) - Honc oino ploirume consentiont Romae duonoro optumo fuise viro, Luciom Scipione. Filios Barbati, consol, censor, aidilis hic fuet apud vos. Hec cepit Corsica aleriaque urbe, dedet Tempestatibus aide meretod.

Jezik zveni starinsko, tudi pravopis je drugačen kot v zlati dobi. Kje je povedkov glagol? Če drži trditev, da je povedkov prostor na koncu stavka, bi v našem napisu ne smel nikjer stati drugače kot na koncu. In vendar ga najdemo v prvem stavku na sredini (consentiont), $v$ drugem prav tako (fuet), $v$ tretjem tudi (cepit) - ugotovimo, da povedkov glagol niti v enem stavku ne stoji na koncu.

$\mathrm{Z}$ razvojem jezika $v$ času se razlik $\mathrm{v}$ besednem redu potemtakem ne da docela pojasniti. Potem ko smo se prepričali na lastne oči, lahko dodamo še, da tudi številke $\mathrm{v}$ zgornji preglednici ne dajejo tako jasne slike, kot se zdi na prvi pogled. Zgornja preglednica je izbor, po naključju sestavljen tako, da daje vtis, da je končne stave

\footnotetext{
${ }^{4}$ Skubic, M., Uvod v romansko jezikoslovje, Ljubljana $1989^{2}\left(1982^{\prime}\right)$
} 
glagola $\mathrm{v}$ zlati dobi veliko in ob koncu antike malo. A če pregled dopolnimo $\mathrm{s}$ podatkom, da stoji glagol pri Cezarjevem sodobniku Varonu na koncu v samo $30 \%$ stavkov, se podoba zamegli. Lahko bi sicer trdili, da piše Varo slabšo latinščino kot Cezar, a s tovrstnim sklepanjem se hitro znajdemo v slepi ulici: pri Plavtu je kriv metrum, pri Varonu slab jezik, pri Ciceronu klavzule; na koncu ostaneta samo Cezar in Livij in onadva postavljata povedkov glagol navadno na konec stavka. Q. E. D.

\section{VZORCI BESEDNEGA REDA V JEZIKU}

Kadar se diahrona razlaga ne izide, poskusimo s sinhrono. Denimo, da je bilo v latinščini možno oboje: postaviti povedkov glagol na konec stavka ali v sredino. Če je bilo res tako, bi morali obe različici besednega reda nekako razporediti po jezikovni ureditvi. Najpreprostejša in najzmernejša razlaga se zdi, da je bil povedkov glagol v govorjeni latinščini večkrat sredi stavka kot v zapisani. V književnih zvrsteh, ki so bližje pogovornemu jeziku, se je povedkov glagol pogosteje znašel sredi stavka. Če se nam zdi takšna domneva neverjetna in neživljenjska, se spomnimo, da tudi sami včasih rečemo:

(8) - Včeraj sem Janeza videl.

in zapišemo:

(9) - Včeraj sem videl Janeza.

Mogoče je torej, da obstajata $\mathrm{v}$ jeziku hkrati dva različna vzorca, le razporejena morata biti tako, da se ne križata. Za primerjavo različnih slogov vzemimo spet nagrobni napis, tokrat z začetka 2. st. po Kr. CIL VI 16631:

(10) - Dis Manibus Miniciae Marcellae Fundani filiae: vixit annos XII, menses XI, dies VII.

O smrti Minicije Marcele piše tudi Plinij Mlajši v enem izmed pisem (Ep. V., 16, 12):

(11) - Tristissimus haec tibi scribo Fundani nostri filia minore defuncta I.../ nondum annos quattuordecim impleverat.

$\mathrm{V}$ pismu je povedek impleverat na koncu, medtem ko je $\mathrm{v}$ nagrobnem napisu na začetku (vixit).

In vendar najdemo pri Cezarju:

(12) - Gallia est omnis divisa in partes tres, quarum unam incolunt Belgae, aliam Aquitani, tertiam, qui ipsorum lingua Celtae, nostra Galli appellantur.

Zakaj ni napisal:

(13) - ** Omnis Gallia in tres partes divisa est, quarum unam Belgae incolunt itd.

Se je zmotil? Ga je zavedel grški vpliv? Pisatelja, ki je zahteval sklanjatev Calypso, Calypsonis gotovo ne. Primerjajmo podobno mesto iz Plinija Starejšega (V, 8, 48):

(14) - Proxima Africae incolitur Aegyptus, introrsus ad meridiem recedens, donec a tergo praetendantur Aethiopes. Inferiorem eius partem Nilus dextera laevaque divisus amplexu suo determinat, Canopico ostio ab Africa, ab Asia Pelusiaco, CLXX passuum intervallo. Quam ob causam inter insulam quidem Aegyptum retulere, ita se findente Nilo, ut triquetram terrae figuram efficial; ideoque multi Graecae litterae vocabulo Delta appellavere Aegyptum 
$\mathrm{V}$ naslednjem poglavju pravi (ibid., 49):

(15) - Summa pars contermina Aethiopiae Thebais vocatur. Dividitur in praefecturas oppidorum, quas nomos vocant.

Ponekod stoji povedkov glagol na koncu, ponekod ne. Toda kaj je za njim tam, kjer ne stoji na koncu?

Prvi stavek (14): incolitur Aegyptus;

drugi del: praetendantur Aethiopes;

zadnji stavek: appellavere Aegyptum.

Vsakič sledi povedkovemu glagolu lastno ime, suh, neolepšan podatek. Po drugi strani imamo v nadaljevanju Thebais vocatur in nomos vocant. Kaže, da nobeno pravilo ne drži povsem.

Oglejmo si v takšni luči še enkrat primer (3), odlomek iz dela Rhetorica ad Herennium (II, 22, 34):

(16) - Item vitiosa expositio est, quae nimium longe repetitur, hoc modo: Omnium malorum stultitia est mater atque materies. Ea parit immensas cupiditates. Immensae porro cupiditates infinitae, immoderatae sunt. Hae pariunt avaritiam. Avaritia porro hominem ad quodvis maleficium impellit. Ergo avaritia inducti adversarii nostri hoc in se facinus admiserunt.

Mesto je v govorniškem priročniku sicer navedeno kot zgled slabega sloga. Poglavitna pomanjkljivost besedila je poseganje predaleč nazaj, a bržkone je pisec namigoval tudi, da sodi $\mathrm{k}$ takšni izpeljavi predaleč nazaj tudi povedek sredi stavka, stava, ki zveni suhoparno.

\section{BESEDNI RED IN SOBESEDILO}

Posvetimo se še začetku in koncu stavka v primeru (16). Drugi stavek se konča $\mathrm{z}$ immensas cupiditates, tretji se začne $\mathrm{z}$ immensae cupiditates; četrti stavek se konča $\mathrm{z}$ avaritiam, peti se začne $\mathrm{z}$ avaritia. $\mathrm{V}$ nobenem primeru ne najdemo med stavkoma ne najdemo slovnične povezave (kot je $\mathrm{v}$ prvem stavku uporaba nanašalnega zaimka mater atque materies $\rightarrow e a$ ), temveč pomensko povezavo. Na začetku stavka stoji beseda, s katero se je končal prejšnji stavek. Takšen prehod med obema stavkoma je opisan tudi v Latinski slovnici prof. Koprive (str. 335): "Zlasti stopi na čelo stavka beseda, ki kaže na prejšnji stavek." Tako sodoben način gledanja, kot ga kaže pričujoči navedek, je v latinski slovnici novost, zato je ugotovitev še pomembnejša. Iz nje sledi, da besedni red ne zadeva samo razmerja znotraj stavka, ampak tudi razmerje med stavki. Takšen je tudi miselni temelj teorije členitve po aktualnosti, dandanes uveljavljene tako med slavisti kot med germanisti. Njeno bistvo je delitev stavka na znano in novo. V slogovno nezaznamovanem stavku najdemo tisto, kar je znano že od prej, na začetku, in tisto, kar izvemo na novo, proti koncu stavka. Če stoji stavek na začetku besedila, stopi na čelo stavčna prvina najsplošnejšega pomena. Iz primera (16) smemo domnevati, da je igrala $v$ latinskem besednem redu določeno vlogo tudi členitev po aktualnosti ${ }^{5}$.

\footnotetext{
${ }^{5}$ Za prvo obšinejše delo o clenitivi po aktualnosti v latinšini velja: Panhuis, D., The Communicative Perspective in the Sentence. A Study of Latin Word Order; Amsterdam 1982.
} 


\section{ZAZNAMOVANI BESEDNI RED}

$\mathrm{V}$ čustveno prizadetem govoru gradimo besedilo velikokrat drugače kot $\mathrm{v}$ navadnem: začnemo s tistim, s čimer bi morali končati, in končamo s tistim, kar bi morali povedati že prej. V govorjenem jeziku je moč tako tvorjene stavke brez težav prepoznati po posebni stavčni intonaciji in glasovno močno poudarjenem začetku stavka. Enako se lahko tudi v latinskem stavku znajde na koncu beseda, ki jo zelo dobro poznamo že od prej. Hofmann v delu Lateinische Umgangssprache ${ }^{6}$ (str. 120) omenja samo primere, ko je zapostavljeni člen na začetku stavka že nakazan $\mathrm{z}$ zaimkom, npr. Rudens 472:

(17) - sed autem, quid si hanc hinc abstulerit quispiam, sacram urnam Veneris?

Vendar se pri Plavtu najdejo tako zapostavljeni (= postavljeni zadaj) tudi stavčni členi brez napovednega zaimka, npr. Truculentus 136ss.:

(18) - Nimis otiosum te arbitror hominem esse. :: Vos mihi dedistis otium.

Podobno Mostellaria 915:

(19) - Bene res nostra est collocata istoc mercimonio.

Zlasti v stavkih s t.i. 'obrnjeno stavo', ko beseda, ki bi morala stati bolj proti koncu stavka, zaradi čustvene prizadetosti govorečega preskoči na začetek, se v besednem redu uveljavi še tretji, namreč izgovorni dejavnik. Že iz svojega jezika vemo, da se krajše besede, zlasti zaimki in členki, rade lepijo na daljše in pri tem izgubijo naglas. Kot vemo, je imela naslonke tudi latinščina. A če si hočemo s pravili o naslanjanju bolj pomagati, moramo za naslonke šteti tudi besede, ki postanejo naslonke samo $\mathrm{v}$ določenem okolju. Da se lahko pod določenimi pogoji $\mathrm{v}$ naslonke spremenijo tudi naglasno sicer samostojne besede, omenja tudi velika Latinska slovnica LHS $^{7}$ (Leumann - Hofmann - Szantyr, II, 398), vendar ne pove natančneje, katerim ali kakšnim besedam se to lahko pripeti. Morda lahko s pomočjo omenjenih 'drugotnih naslonk' odgovorimo na vprašanje, s katerim se zlasti raziskovalci Plavtovega jezika že dolgo ukvarjajo: $\mathrm{v}$ njegovih stavkih se začno pogosto nekje na sredini kopičiti kratke besede, zlasti zaimki in oblike pomožnega glagola. J. Schneider (De enuntiatis secundariis interpositis quaestiones Plautinae ${ }^{8}$ ) meni, da se zaimki združujejo, da bi bili enakovredni daljšim besedam. J. Marouzeau', veliki raziskovalec latinskega sloga, ima kopičenje kratkih besed celo za Plavtovo slogovno šibkost. Primer za tovrstno 'slogovno šibkost' je izrek homo homini lupus, iz komedije Asinaria v zgornjem primeru (5). Zlasti stavo osebnih zaimkov laže pojasnimo, če dopolnimo pravila za rabo. Poleg poudarjene in nepoudarjene rabe je obstajala $v$ pogovorni latinščini še ena možnost za uporabo osebnega zaimka: zaimek se postavi za glagolsko obliko, a ne izraža nasprotja kot v znanem zgledu

(20) Ego canto, tu ludis.

Zaimek $v$ tovrstnih stavkih ublaži poudarjeno glagolsko obliko (podobno rabo pozna srbohrvaščina). Nekaj primerov iz Plavta:

(21) - Rudens 1013: Abeo ego illinc.

(22) - Captivi 328: Odi ego aurum.

\footnotetext{
6 Hofmann, J. A., Lateinische Umgangssprache; Heidelberg 1936

7 Leumann, M. - Hofmann, J. - Szantyr, A., Lateinische Syntax und Stilistik; München 1965

8 Dresden 1937 (diss.)

9 Marouzeau, J., La construction de particules de liaison; Revue des études latines 26, 1948, $235-267$.
} 
(23) - Stichus 23: Novi ego illum.

$\mathrm{Za}$ besedni red je pomembno dejstvo, da stoji takšen osebni zaimek vselej za glagolom kot naslonka, ker je glagol dodatno poudarjen. Tako doseženega pomenskega odtenka ni prav lahko izraziti $v$ slovenskem prevodu, saj slovenščina takšne rabe zaimka ne pozna. Podobno, po izvoru, kot smo že povedali, pogovorno zvezo, je Salustij v delu Bellum lugurthinum $(85,1)$ položil na jezik Mariju v slovitem Scio ego, Quirites /.../ in dosegel, da zveni začetek govora ponosno, a ljudsko.

\section{BESEDNI RED IN RAZUMEVANJE BESEDILA}

Poskusimo za konec $\mathrm{z}$ vsem, kar smo našteli, razložiti kaj od besednega reda $\mathrm{v}$ odlomku iz Plavtove komedije Stichus. Vsebina odlomka je naslednja: starec Antifon bi rad, da bi mu zet Epignomus podaril mlado sužnjo; ker mu je vpričo drugega zeta Pamfilipa nerodno prositi naravnost, se zateče k priliki (apologus) (538ss.):

(24) - Antipho: Prius quam abis, praesente ted huic apologum agere unum volo. Pamphilippus: Maxume.

A.: Fuit olim, quasi ego sum, senex. Ei filiae duae erant, quasi nunc meae sunt, duobus nuptae fratribus, quasi nunc meae sunt vobis.

Epignomus: Miror, quo evasurust apologus.

A.: Erant minori illi adulescenti fidicina et tibicina; peregre advexerat, quasi nunc tu. Sed ille erat caelebs senex, quasi ego nunc sum.

E.: Perge porro. Praesens hicquidem est apologust.

A.: Deinde senex ille illi dixit, cuius erat tibicina, quasi ego nunc tibi dico.

E.: Ausculto atque animum advorto sedulo.

A.: "Ego tibi meam filiam, bene quicum cubitares, dedi; nunc mihi reddi ego aequom esse abs te, quicum cubitem, censeo."

E.: Quis istuc dicit? An ille quasi tu?

A.: Quasi ego nunc dico tibi. "Immo duas dabo," inquit ille adulescens, "una si parum est; et si duarum paenitebit, addentur duae."

O besednem redu v navedenem odlomku je moč povedati naslednje:

1.) Besedilo prilike se začne $z$ glagolom esse kot stavčno prvino najsplošnejšega pomena.

2.) Zaimek ei stoji na začetku stavka kot navezava na prejšnji stavek.

3.) Osebek apologus stoji dvakrat na koncu stavka, ker je vprašanje ( $v$ drugem primeru vzklik) neposredno vezano na sobesedilo. Plavt je $\mathrm{z}$ obrnjeno stavo obakrat izrazil mladeničevo presenečenje.

4.) Zaimek ego stoji za glagolsko obliko reddi, da ublaži ostrino izjave.

5.) Glagolska oblika addentur stoji na začetku glavnega stavka kot posredna navezava na paenitebit $\mathrm{v}$ odvisniku.

$\mathrm{O}$ besednem redu $\mathrm{v}$ odlomku lahko povemo kaj malo zanesljivega, kajti besedni red je $\mathrm{v}$ jeziku, kot je latinščina, stičišče številnih silnic, zato ga ni moč razlagati zgolj z enim pravilom ali dvema. Ker deluje kot izrazilo na več jezikovnih ravninah hkrati, ga je treba pogosto utemeljevati hkrati s slovničnimi, besediloslovnimi in slogovnimi zakonitostmi. 


\section{SUMMARY}

If one attempts to deal with word order problems in Latin and Greek, the difficulties that he encounters are considerable. It is hardly possible to formulate a set of rules by means of which one could give a comprehensive analysis of word order phenomena in Latin and Greek as a whole. In descriptive grammar, the word order is treated very extensively, yet the rules that are given are not as complete as one might expect. Grammatical categories of subject, object and predicate serve well as means of identifying the sentence constituents. However, an assumption can be made that the word order is to be explained by means of independent text patterns or general discourse intention of the speaker/writer. 